\title{
Pragmatic Recommendations for Safety while Caring for Hospitalized Patients with COVID-19 in Low- and Middle-Income Countries
}

\begin{abstract}
Rebecca Inglis, ${ }^{1}$ Lia Barros, ${ }^{2}$ William Checkley, ${ }^{3,4}$ Elif A. Cizmeci, ${ }^{5}$ Faith Lelei-Mailu, ${ }^{6}$ Rajyabardhan Pattnaik, ${ }^{7}$ Alfred Papali, ${ }^{8}$ Marcus J. Schultz, ${ }^{9,10,11}$ and Juliana C. Ferreira ${ }^{12 \star}$ for the COVID-LMIC Task Force and the Mahidol-Oxford Research Unit (MORU) ${ }^{1}$ Lao-Oxford-Mahosot Hospital-Wellcome Trust Research Unit (LOMWRU), Mahosot Hospital, Vientiane, Lao People's Democratic Republic; ${ }^{2}$ Division of Cardiology, University of Washington, Seattle, Washington; ${ }^{3}$ Division of Pulmonary and Critical Care, Department of Medicine, School of Medicine, Johns Hopkins University, Baltimore, Maryland; ${ }^{4}$ Center for Global Non-Communicable Disease Research and Training, School of Medicine, Johns Hopkins University, Baltimore, Maryland; ${ }^{5}$ Interdepartmental Division of Critical Care Medicine, Sunnybrook Health Sciences Centre, University of Toronto, Toronto, Canada; ${ }^{6}$ Department of Quality Health and Safety, AlC Kijabe Hospital, Kijabe, Kenya; ${ }^{7}$ Division of Critical Care Medicine, Ispat General Hospital, Rourkela, India; ${ }^{8}$ Division of Pulmonary and Critical Care Medicine, Atrium Health, Charlotte, North Carolina; ${ }^{9}$ Department of Intensive Care, Amsterdam University Medical Centers, Amsterdam, The Netherlands; ${ }^{10}$ Department of Clinical Tropical Medicine, Mahidol University, Bangkok, Thailand; ${ }^{11}$ Mahidol-Oxford Tropical Medicine Research Unit (MORU), Mahidol University, Bangkok, Thailand; ${ }^{12}$ Divisao de Pneumologia, Instituto do Coracao, Hospital das Clinicas HCFMUSP, Faculdade de Medicina,
\end{abstract} Universidade de Sao Paulo, Sao Paulo, Brazil

\begin{abstract}
Infection prevention and control measures to control the spread of COVID-19 are challenging to implement in many low- and middle-income countries (LMICs). This is compounded by the fact that most recommendations are based on evidence that mainly originates in high-income countries. There are often availability, affordability, and feasibility barriers to applying such recommendations in LMICs, and therefore, there is a need for developing recommendations that are achievable in LMICs. We used a modified version of the GRADE method to select important questions, searched the literature for relevant evidence, and formulated pragmatic recommendations for safety while caring for patients with COVID-19 in LMICs. We selected five questions related to safety, covering minimal requirements for personal protective equipment (PPE), recommendations for extended use and reuse of PPE, restriction on the number of times healthcare workers enter patients' rooms, hand hygiene, and environmental ventilation. We formulated 21 recommendations that are feasible and affordable in LMICs.
\end{abstract}

\section{INTRODUCTION}

The virus that causes COVID-19, SARS-CoV-2, is a new coronavirus, which shares many characteristics with known respiratory viruses, such as the viruses that cause influenza, SARS, and Middle East respiratory syndrome (MERS). ${ }^{1}$ However, SARS-CoV-2 has features which have resulted in a pandemic of unprecedented proportions, including the ability to transmit from patients who are asymptomatic or presymptomatic. ${ }^{2}$

High rates of healthcare worker infections and clusters in health facilities have been reported. ${ }^{3,4}$ Based on two reports from Italy in early March 2020, an estimated $20 \%$ of frontline healthcare workers were infected with the virus, with healthcare workers making up $9.0 \%$ of the total cases infected. ${ }^{5,6}$ Data from China showed that medical facility staff made up $4.4 \%$ of cases there, with 23 deaths reported as of June. ${ }^{7}$

Protecting the hospital workforce and preventing nosocomial transmission is of paramount importance, but especially challenging in many low- and middle-income countries (LMICs). ${ }^{8}$ These challenges were illustrated in an online survey of 936 healthcare workers in Latin America, which showed that $24.5 \%$ of respondents did not have safety policies and procedures in the workplace and demonstrated limited access to essential items of personal protective equipment (PPE), with $43.9 \%$ reporting no access to N95 respirators. ${ }^{9}$

Many of the infection control recommendations for COVID19 are based on evidence derived from studies mainly conducted in high-income countries (HICs). However, there are often availability, affordability, and feasibility barriers to

*Address correspondence to Juliana C. Ferreira, Divisao de Pneumologia, Instituto do Coracao, Hospital das Clinicas HCFMUSP, Faculdade de Medicina, Universidade de Sao Paulo, Av. Dr. Enéas de Carvalho Aguiar, 455 andar, bloco 2, sala 1, Sao Paulo 05403000 ,

Brazil. E-mail: juliana.ferreira@hc.fm.usp.br applying such recommendations in LMICs. Moreover, our current understanding of the relative contribution of different routes of transmission for COVID-19 is incomplete. ${ }^{10}$ This presents a challenge when deciding which safety measures to prioritize, especially in the context of limited resources.

We provide a list of recommendations and suggestions adapting evidence from HICs after pragmatic, experiencebased appraisal. A summary of the recommendations is shown in Table 1.

\section{METHODS}

A full description of the methods is provided in the appendix. In brief, we formulated a set of questions regarding safety for patients and healthcare workers caring for patients with suspected or confirmed COVID-19. The list of questions was reviewed for content and clarity by other members of the COVID-LMIC Task Force. After approval, the safety subgroup assigned one or two members to search the literature for evidence to answer each of the questions. The literature search was performed in a minimum of one general database (i.e., MEDLINE and EMBASE) and the Cochrane Libraries, including articles pertaining to COVID-19, SARS, MERS, and other respiratory viruses.

We selected relevant publications, appraised the evidence, and classified the quality of evidence as high, moderate, low, or very low. Recommendations were rated as strong or weak, depending on the quality of evidence and several other factors such as availability, affordability, and feasibility in LMICs. A strong recommendation was worded as "we recommend. .." and a weak recommendation as "we suggest. ..," followed by the quality of evidence. A number of recommendations could remain "ungraded" (UG), when, in the opinion of the subgroup members, such recommendations were not conducive for the process described earlier (Table A2). The recommendations were reviewed by the 
safety subgroup in an iterative process and were later reviewed by the entire task force in two rounds.

\section{QUESTIONS}

We formulated five clearly defined questions regarding safety:

1. Which items of PPE are mandatory when caring for a patient with COVID-19?

2. Is reuse, extended use, or the substitution of alternative items of PPE a safe alternative to standard PPE when providing care for COVID-19 patients?

3. In COVID-19 patients, is there evidence to guide the number of times that a healthcare worker should enter a patient's room to reduce the risk of infection and preserve PPE while maintaining patient safety?

4. What methods of hand hygiene are effective for COVID-19?

5. Can natural ventilation be used in lieu of mechanical environmental ventilation to carry out care involving aerosolgenerating procedures for patients with COVID-19?

The questions and recommendations are discussed as follows:

Question 1: In LMICs, which items of PPE are mandatory when caring for a patient with COVID-19? Rationale. Infection of healthcare workers is a major concern for the COVID-19 pandemic. One study found that in 476 hospitals in China, there were 2,055 healthcare workers who tested positive for COVID-19 in 3 months alone. ${ }^{11}$

Our current understanding of COVID-19 transmission is that the disease is predominantly spread from person to person through the air, via droplets and aerosols, especially at short ranges. ${ }^{12}$ It is likely that COVID-19 also spreads via fomites. ${ }^{12}$ The WHO recommends that healthcare workers require barrier precautions only for standard patient care, comprising a single pair of gloves, eye protection, a long-sleeved gown, and a surgical mask. ${ }^{13}$ The addition of inhalational protection, in the form of an N95 respirator, is recommended for aerosolgenerating procedures. ${ }^{13}$ Some country-specific guidelines recommend inhalational protection for all patient contacts. ${ }^{14,15}$ Others recommend differing degrees of barrier protection with coveralls, rather than gowns, or the addition of head and neck coverings, double gloves, and protective footwear or shoe covers. ${ }^{14}$ By contrast, other countries recommend less barrier protection than the $\mathrm{WHO}$, including the substitution of aprons for gowns for some types of patient contacts. ${ }^{16,17}$

Because of the large numbers of patients with COVID-19 being admitted to hospitals and widespread shortages of PPE, it is urgent to understand what are the minimum essential items required to keep healthcare workers safe. ${ }^{18}$

Search results. The following terms were used, either as MeSH terms or as free text words: "COVID-19," "personal PPE," "healthcare worker," and "precautions" in MEDLINE to identify articles as of June 15, 2020 that discussed the minimum levels of personal PPE needed to safely care for patients with COVID-19. This search produced 10 articles, which were reviewed for applicability to the research question, and two appropriate studies were identified. Further review of the references from both studies and review of the references from the WHO guidelines revealed an additional seven articles that were included in this review.
Evidence. Most studies that look at the efficacy of PPE are studies of simulated transmission scenarios using fluorescent markers or nonpathogenic organisms, rather than real-world research. ${ }^{19}$ Of the empirical studies, few relate directly to COVID-19, with most data being extrapolated from other viruses.

Face masks and eye protection. A recent systematic review and meta-analysis looked at the minimum physical distancing, face masks, and eye protection needed to prevent person-toperson transmission of betacoronaviruses. ${ }^{20}$ The 172 studies included were conducted in 16 countries, of which one was lower middle-income and two were upper middle-income economies. Patients with COVID-19 accounted for 6,674 of the 25,697 patients in the studies, and the remainder had SARS or MERS. The authors concluded that face mask use could result in a large reduction in the risk of transmission, with $3.1 \%$ transmission with a face mask versus $17.4 \%$ with no face mask. Eye protection, defined as goggles or face shield, was also associated with less transmission than no eye protection, with $5.5 \%$ transmission versus $16.0 \%$, respectively.

Comparing face masks to N95 respirators, subgroup analysis in the same study suggested that N95 respirators might provide more protection from infection than surgical and cotton masks. ${ }^{20}$ This conclusion has been questioned because it is based on a post hoc Bayesian analysis of two independent analyses, rather than a direct comparison of N95 respirators and medical masks. ${ }^{21}$ By contrast, low certainty evidence from a 2016 meta-analysis that looked at a wider range of viral respiratory infections, but including coronaviruses, suggested that medical masks and N95 respirators may offer similar protection against transmission during nonaerosol-generating care. ${ }^{22}$ A second meta-analysis tackling a similar question was carried out by the Chinese Cochrane Centre and published in March 2020. ${ }^{23}$ They included data from three additional randomized controlled trials in their analysis, but again, there were no patients with COVID-19. The authors noted that although N95 respirators may be more protective against the transmission of respiratory viruses in laboratory studies, the benefit was not borne out in empirical work. They concluded that the use of N95 respirators compared with surgical masks were not associated with a lower risk of laboratory-confirmed respiratory viral infections.

These findings would tentatively support the use of surgical masks for standard patient care, thereby conserving N95 respirators for aerosol-generating procedures. It is important to note that although $\mathrm{N} 95$ respirators, surgical masks, and eye protection show a reduction in risk of transmission, they do not afford complete protection in any study. ${ }^{20,24,25}$

Elastomeric respirators, half facepiece, or full facepiece tight-fitting respirators have been suggested as alternatives to N95 respirators during surges because they can be repeatedly used, cleaned, disinfected, stored, and reused. However, they are rarely available in LMICs and therefore are not included in the recommendations.

Gowns and coveralls. A Cochrane review that explored what type of PPE or combination of PPE gives healthcare workers the best protection was updated in May 2020 to include a total of 24 studies with 2,278 participants. ${ }^{19}$ The authors found that "there is low- to very low-certainty evidence that covering more parts of the body leads to better protection but usually comes at the cost of more difficult donning or doffing and less user comfort". Accordingly, the review found 
TABLE 1

Recommendations and suggestions for safety while caring for patients with COVID-19 in low- and middle- income countries

Which items of PPE are mandatory when caring for a patient with COVID-19?

-We recommend that healthcare workers providing direct care to suspected or confirmed COVID-19 patients should wear a surgical mask, a single pair of gloves, eye protection (goggles and face shield), and a long-sleeved gown, provided no aerosol generating procedures are being performed (strong recommendation, low quality of evidence).

- We recommend that healthcare workers providing direct care to suspected or confirmed COVID-19 patients should wear an N95 respirator when aerosol generating procedures are being carried out, in addition to a single pair of gloves, eye protection, and a long-sleeved gown (strong recommendation, low quality of evidence).

- We suggest that institutions provide practical training on how to don and doff PPE safely and establish a policy on what PPE to wear in different scenarios (ungraded best practice statement).

-We recommend that all items of PPE for use in a healthcare setting meet the minimum manufacturing standards recommended by the WHO (ungraded best practice statement).

- We recommend that all healthcare workers be alert to the risks posed by substandard and counterfeit PPE and be familiar with how to spot suspect items (best practice statement).

Is reuse, extended use, or the substitution of alternative items of PPE a safe alternative to standard PPE when providing care for COVID-19 patients in LMICs?

- We suggest the extended use of surgical masks and N95 respirators in preference to reuse as long as the item does not become wet, damaged or difficult to breathe through, in which case it should be discarded (weak recommendation, low quality of evidence).

- If a reuse strategy is adopted for N95 respirators, we suggest that one of the three approved methods for decontamination should be used (hydrogen peroxide vapor, moist heat or UV-C radiation). If none are possible, then storing the mask for seven days before reuse by the original wearer is preferable to immediate reuse as a last resort measure (weak recommendation, low quality of evidence).

- If a reuse strategy is adopted for N95 respirators, we suggest that face shields be used in conjunction in order to reduce surface contamination of the respirator (weak recommendation, low quality of evidence).

- We suggest that surgical masks and disposable gloves are not reused (weak recommendation, very low quality of evidence).

- We suggest that cloth masks be used as a last resort by staff as these are better than no protection at all, preferably used alongside face shields (ungraded best practice statement).

In LMICs, is there evidence to guide the number of times that a healthcare worker should enter a COVID-19 patient's room to reduce the risk of infection and preserve PPE while maintaining patient safety?

-We suggest that healthcare workers should enter the patient's room as many times as needed to provide essential patient care but minimize the exposure time in the room once activities are completed (ungraded best practice statement).

- We suggest minimizing the number of times that a healthcare provider needs to enter the room of a patient with COVID-19 by:

a. Rationalizing medication dosing and administration times

b. Timing a patient's turns to coincide with medication administration and bundling other essential activities

c. Establishing a means of monitoring the patient remotely, e.g. checking on the patient and the monitor through the window, setting the monitor and ventilator alarms to maximum volume

d. Perform suctioning of the endotracheal tube as needed rather than routinely

e. Providing awake patients with a means to attract the attention of staff when required, whether mobile phone, bell or improvised rattle - (ungraded best practice statement)

What methods of hand hygiene are effective for COVID-19 in LMICs?

-When caring for patients with COVID-19, we recommend the use of WHO-approved alcohol-based hand sanitiser for a full 30 seconds, with a sufficient volume to ensure complete hand coverage, before and after each patient contact (strong recommendation, moderate quality of evidence).

- If WHO-approved alcohol-based hand sanitiser is not available, or when hands are visibly dirty, we recommend washing hands with soap \& water for 40-60 seconds, followed by drying with a paper towel, before and after each patient contact (strong recommendation, moderate quality of evidence).

-We suggest that alcohol-based hand sanitiser is locally produced following the WHO specifications where commercial formulations are not available (ungraded best practice statement).

Can natural ventilation be used in lieu of mechanical environmental ventilation to carry out care involving aerosol-generating procedures for patients with COVID-19 in LMICs?

-Where mechanical air ventilation is not available, we recommend that natural ventilation can be an acceptable alternative when carrying out aerosol generating procedures for patients with COVID-19, provided flow rates of at least $160 \mathrm{~L} / \mathrm{second} /$ patient or 12 air changes per hour are achieved. Where aerosol generating procedures are not performed, $60 \mathrm{~L} /$ second/patient or 6 air changes per hour is sufficient (strong recommendation, moderate quality of evidence).

-Where it is not possible to formally measure air flow, we recommend the use of a $\mathrm{CO}_{2}$ analyzer to measure indoor $\mathrm{CO}_{2}$ as a proxy indicator of ventilation (strong recommendation, moderate quality of evidence).

-We suggest that the room where aerosol-generating procedures are performed should be selected or modified to include some or all of the following design features, using the design principles from the WHO Natural Ventilation guidelines:

a. Large, open windows

b. Windows on more than one wall; opposite walls if possible

c. High ceilings

d. Additional air vents; open skylights or whirligig roof ventilator

(strong recommendation, moderate quality of evidence)

- In a facility with natural ventilation, we recommend that the windows and other ventilation vents should be left open at all times to allow airflow. The door to the rest of the hospital should be left shut (strong recommendation, moderate quality of evidence).

- In a setting with insufficient natural ventilation, we recommend that a hybrid or mixed-mode system of air ventilation be created by installing exhaust fans in conjunction with the natural ventilation measures (strong recommendation, moderate quality of evidence).

- We recommend measures to improve natural ventilation should be taken in all areas where COVID-19 patients are being cared for, whether aerosol-generating procedures are being carried out or not (strong recommendation, low quality of evidence). 
that coveralls may offer the best protection from contamination during patient contact but are uncomfortable to wear and the most difficult item to remove safely. ${ }^{19}$ Likewise, gowns provide more protection than aprons but are harder to remove. $^{19}$

Gloves. No studies were identified that looked at glove use versus no glove use. Pooled data from six small SARS studies showed that consistent glove use versus inconsistent glove use led to a decrease in the risk of virus transmission, but this was not statistically significant. ${ }^{19}$ The practice of doublegloving is recommended by some organizations because it is thought to facilitate safe PPE removal. Although there is some evidence that this practice may reduce the risk of contamination, it is of very low certainty. ${ }^{19}$

Training. The Cochrane review of PPE was unable to draw a conclusion on which doffing procedure was the safest, but having a second person providing verbal instructions during doffing may improve safety. ${ }^{19}$ More active methods of training, including face-to-face training, computer simulation, and video training, were associated with fewer errors in PPE removal than passive training delivered as written material only or a traditional lecture. ${ }^{19}$ Teaching the safe use of PPE using clinical simulation may help recreate the high cognitive load of clinical practice. ${ }^{26}$

Availability, feasibility, affordability, and safety. The availability of different items of PPE in LMICs is unknown and is unlikely to be uniform, especially as the number of cases increases and countries face different procurement challenges. The cost implications of different combinations of PPE is also challenging to factor into international recommendations, given the wide variations in retail price and the impact of large donations.

With regard to safety, there is a major concern regarding the quality of some of the PPE entering the supply chain during the COVID-19 pandemic. This is of particular concern with respirators but has also been reported to affect face masks, gowns, and gloves. ${ }^{27,28}$ Many countries have reported receiving poor quality and counterfeit items. ${ }^{27,29}$ There are national and international manufacturing standards that each item of PPE should meet. ${ }^{30}$ Unfortunately, even products that meet the certification requirements can still be substandard with faked certificates or inadequate checks of the raw materials. Recommendations on how to spot poor-quality PPE have been published. ${ }^{28,31,32}$ Healthcare workers should report any suspicions they have immediately and not use any potentially faulty items while the issue is investigated.

Another safety concern with regard to PPE is heat stress. ${ }^{19}$ In LMICs, it is more likely that hospitals will not be airconditioned, so breathability and comfort are important considerations. This concern was factored into the decision to recommend gowns over coveralls.

Recommendations and suggestions.

1. We recommend that healthcare workers providing direct care to suspected or confirmed COVID-19 patients wear a surgical mask, a single pair of gloves, eye protection (goggles or face shield), and a long-sleeved gown, provided no aerosol-generating procedures are being performed (strong recommendation and low quality of evidence).

2. We recommend that healthcare workers providing direct care to suspected or confirmed COVID-19 patients wear an N95 respirator when aerosol-generating procedures are being carried out, in addition to a single pair of gloves, eye protection, and a long-sleeved gown (strong recommendation and low quality of evidence).

3. We suggest that institutions provide practical training on how to don and doff PPE safely and establish a policy on what PPE to wear in different scenarios (UG best practice statement).

4. We recommend that all items of PPE for use in a healthcare setting meet the minimum manufacturing standards recommended by the WHO (UG best practice statement).

5. We recommend that all healthcare workers be alert to the risks posed by substandard and counterfeit PPE and be familiar with how to spot suspect items (UG best practice statement).

Question 2: Is reuse, extended use, or the substitution of alternative items of PPE a safe alternative to standard PPE when providing care for COVID-19 patients in LMICs? Rationale. The COVID-19 pandemic has led to significant shortages of medical grade PPE globally. This has driven the need to maximize the use of the supplies that are available or to source acceptable alternatives. It is imperative however to prioritize the safety of healthcare workers when considering these emergency measures. This review will consider five types of PPE: surgical masks, N95 respirators, eye protection, gowns, and gloves.

Reuse is taken to mean the practice of using an item of PPE for a patient encounter, removing it, and then putting it back on again for an encounter with another patient. Generally, this process will include reprocessing, using a method of disinfection to decontaminate the item before reuse. Extended use refers to the practice of using the same item of PPE for encounters with multiple patients without removing it in between. Often this will be in a cohort of patients with confirmed COVID-19.

Search results. A search on PubMed as of May 26, 2020 using the search terms "masks," "face shields," "gowns," "cloth gowns," "gloves," "PPE," "COVID-19," "low resource settings," "LMIC," "reuse," and "extended use," either alone or in combinations, yielded no articles. Therefore, we reviewed pertinent findings from all settings.

Evidence. Face masks. To date, there is no evidencebased method to safely reprocess surgical masks for reuse without damaging them. ${ }^{33}$ The authors of a recent systematic review on the topic were only able to find one study that addresses mask decontamination and were unable to make any recommendations. ${ }^{34}$

The evidence base for extended use of surgical masks is similarly scant. Our search did not find any relevant studies, despite the practice being widely recommended in preference to reuse during critical shortages. Nevertheless, the cited argument that extended use avoids the risk of selfcontamination during repeated donning and doffing seems plausible. $^{35}$

The use of homemade cloth masks of different fabrics has been studied as an alternative means to mitigate the challenges of shortages of surgical masks. A randomized control study comparing cloth masks with surgical masks found that cloth masks may increase the risk of infections possibly because of their reuse, moisture retention, and poor filtration. ${ }^{36}$

Some studies have attempted to evaluate the efficacy of homemade face mask materials in stopping transmission of 
small particles equal to those of a virus. ${ }^{20,25}$ Spraying 20- to 1000-nm-size particles at different face velocities to multiple different types of fabric, the authors found that although fabric materials may only provide a minimal level of respiratory protection to the wearer against virus-sized aerosol particles, they did perform similarly to surgical masks. ${ }^{25}$ The authors further identified that wearing fabric masks tightly to maximize a seal around the edges was the most important aspect of use. These findings suggest that certain fabric masks may offer a feasible and affordable alternative to healthcare workers caring for COVID-19 patients when surgical masks are not available.

N95 respirators. Like surgical masks, the extended use of N95 respirators is recommended over reuse. ${ }^{35}$ Extended use avoids the risk that the respirator will fit less well after repeated donning and the risk that the reprocessing will lead to impaired filtration efficiency or incomplete decontamination. ${ }^{35,37} \mathrm{Nev}-$ ertheless, there is still a concern that extended use can lead to reduced respiratory protection. ${ }^{38}$ There is some evidence that respirators can be reprocessed and reused for up to five times, ${ }^{39,40}$ but the U.S. CDC alerts that other variables affect the effectiveness of extended use and reuse and recommends consultation with occupational health and infection control departments. ${ }^{41}$

The three evidence-based methods for N95 decontamination without significantly damaging the respirator include hydrogen peroxide vapor, moist heat, or ultraviolet C (UV-C) radiation. ${ }^{42}$ Reprocessing protocols and regular reviews of the emerging evidence are available. ${ }^{43}$ There is also the option of simply storing the respirator for a period of time before reuse to await viral inactivation. There is insufficient evidence to confirm that this method is safe or effective, and it does not decontaminate mold or bacteria. However, a non-peer-reviewed analysis from the N95 DECON consortium concludes "for an N95 (respirator) that is stored individually in a clean and breathable container at room temperature, a 7-day waiting period before reuse is expected to significantly decrease risk of exposure to SARS-CoV-2." 44

Gloves. The extended use of gloves for more than one patient, even within a cohort of patients with confirmed COVID19 , is strongly discouraged by the WHO. They also discourage reuse of gloves. ${ }^{13}$

Gloves are generally manufactured for single use, but their reuse has been considered in instances where their availability is not guaranteed. One study showed that multiple disposable glove brands maintained their integrity when treated with up to six applications of alcohol-based hand rub, although that study did not examine the efficacy of decontamination. ${ }^{45}$ Research and permeation data also show that some disposable gloves can be disinfected up to 10 times with diluted bleach solution. ${ }^{46,47}$ Alternatives to medical gloves have been considered, including disposable gloves from the catering and cleaning industries.

Eye protection. Regarding eye protection, both goggles and some types of face shield can be reused by cleaning with soap and water, followed by disinfection with alcohol-based solutions or bleach $0.1 \%{ }^{48,49}$ Where the recommended form of eye protection is not available, safety glasses with extensions to cover the sides of the eyes are a suggested alternative, although the U.S. CDC cautions that these will not protect eyes from all splashes and sprays. ${ }^{13,15}$ Regular glasses are not felt to be an adequate substitute because they do not offer lateral eye protection. One study suggested that face shields are preferred to goggles because they have been shown to be beneficial, protecting the respirator masks from surface contamination. ${ }^{50,51}$ Because of their short supply, there have been studies published on local production of the face shields, with readily available materials and clear instructions on their dimensions. ${ }^{52}$

Gowns. We did not find any empirical evidence addressing the extended use or reuse of disposable medical gowns. Alternative items that can be used when gowns are not available include long-sleeved laboratory coats, raincoats, rain ponchos, or bin bags. ${ }^{13,53}$ Purpose-made cloth gowns can also be manufactured locally.

The different methods to reprocess cloth gowns include machine washing with warm water between $60^{\circ}$ and $95^{\circ}$ and $a$ laundry detergent and allowing to air dry. Other methods include soaking in hot water, followed by a manual wash with soap and water, soaking in $0.1 \%$ chlorine, or use of an autoclave when available. ${ }^{54}$

Other measures. Other ways of minimizing the PPE consumption include discharging all stable patients and designating a dedicated healthcare team without medical risk factors for disease severity who can reuse PPE or use for extended periods. Restricting healthcare workers not involved in direct patient care, such as food delivery, and bundling of activities for those involved in direct care will also reduce PPE consumption rate, hence preserving supply. ${ }^{55}$

Availability, feasibility, affordability, and safety. The availability of disposable PPE in LMICs remains a challenge, and one that is likely to continue. However, the proposed methods for cleaning and disinfecting goggles, face shields, and cloth gowns should be feasible in almost all settings. The proposed methods of reprocessing the PPE should be adhered to ensure that the healthcare workers are protected despite reuse. ${ }^{13}$ The challenge that stands for many LMICs will be the safe reprocessing of N95 respirator masks.

Local production of cloth gowns is feasible in most settings and should be considered. The cost of reprocessing them (labor and the supplies) should also be considered. Local production of face shields can be implemented by using materials which are usually available in most LMICs. ${ }^{52}$

Recommendations and suggestions.

1. We suggest the extended use of surgical masks and N95 respirators in preference to reuse as long as the item does not become wet, damaged, or difficult to breathe through, in which case it should be discarded (weak recommendation and low quality of evidence).

2. If a reuse strategy is adopted for N95 respirators, we suggest that one of the three approved methods for decontamination be used (hydrogen peroxide vapor, moist heat, or UV-C radiation). If none are possible, then storing the mask for 7 days before reuse by the original wearer is preferable to immediate reuse as a last resort measure (weak recommendation and low quality of evidence).

3. If a reuse strategy is adopted for N95 respirators, we suggest that face shields be used in conjunction to reduce surface contamination of the respirator (weak recommendation and low quality of evidence).

4. We suggest that surgical masks and disposable gloves not be reused (weak recommendation and very low quality of evidence) 
5. We suggest that cloth masks be used as a last resort by staff because these are better than no protection at all, preferably used alongside face shields (UG best practice statement).

Question 3: In LMICs, is there evidence to guide the number of times that a healthcare worker should enter a COVID-19 patient's room to reduce the risk of infection and preserve PPE while maintaining patient safety? Rationale. Healthcare workers around the world are dedicated to providing the best possible standard of care to their patients. This must be balanced against the safety of those providers. In settings where PPE is scarce and there are limited numbers of staff to provide patient care, there is an additional need to ensure efficient and equitable use of these resources.

Search results. To determine how many times healthcare workers should enter a patient's room to minimize the risk of infection while also taking PPE shortages into consideration, we conducted a review of available literature using the search terms "healthcare provider," "precautions," and "COVID-19" in different combinations in MEDLINE through June 9, 2020. The search yielded 22 articles. After reading titles and abstracts, we identified 10 articles that potentially met the criteria. None was from a randomized controlled trial, and none provided information about limiting the number of times healthcare workers enter a room for mechanical ventilator checks and changes, or for suction care. Of these, two were written by authors from an upper middle-income country, ${ }^{56,57}$ and none were written by authors from a lower- or lower middle-income country.

Evidence. Data to support evidence-based practice of healthcare worker contact with COVID-19 patients are scarce. None of the articles specifically discussed limiting the number or duration of patient care activities by healthcare workers. ${ }^{56-65}$ One study noted that the median estimated time of overall exposure to the patient was 120 minutes in healthcare workers who became infected with COVID-19 compared with 25 minutes in those who did not become infected. ${ }^{61}$

An article that provided recommendations on precautions, indications, prioritization, and protection for patients and healthcare workers involved in cardiovascular imaging procedures posed the important question "will undertaking the study (procedure) substantially change patient management or will it be lifesaving?" that should be asked before conducting any procedure. ${ }^{60}$ In particular, elective, nonurgent, and routine care may be postponed or even cancelled. Another article focused on recommendations for tracheostomy noted the importance of minimizing the number of staff who enter a room to conduct a procedure or provide patient care at any point in time. ${ }^{65}$ Staff who enter the room of a patient with known or suspected COVID-19 should adhere to standard precautions and use a respirator or face mask, gown, gloves, and eye protection. ${ }^{13}$

Availability, feasibility, affordability, and safety. Every patient deserves the best treatment available in the circumstances even when resources are scarce. Healthcare workers have a duty of care to promote their patients' welfare within the constraints of the resources available. At the same time, healthcare workers are also owed a duty of care, and all necessary measures should be taken to ensure their safety, including the provision of sufficient PPE. These principles apply anywhere in the world, irrespective of income.

Recommendations.

1. We suggest that healthcare workers enter the patient's room as many times as needed to provide essential patient care but minimize the exposure time in the room once activities are completed (UG best practice statement).

2. We suggest minimizing the number of times that a healthcare provider needs to enter the room of a patient with COVID-19 by:

a. Rationalizing medication dosing and administration times

b. Timing a patient's turns to coincide with medication administration and bundling other essential activities

c. Establishing a means of monitoring the patient remotely, for example, checking on the patient and the monitor through the window and setting the monitor and ventilator alarms to maximum volume

d. Perform suctioning of the endotracheal tube as needed, rather than routinely

e. Providing awake patients with a means to attract the attention of staff when required, whether mobile phone, bell, or improvised rattle (UG best practice statement).

Question 4: What methods of hand hygiene are effective for COVID-19 in LMICs? Rationale. Fomite transmission has not yet been directly demonstrated for SARS-CoV-2, but it has been for other respiratory viruses, including coronaviruses. ${ }^{66}$ It is likely that transmission of SARS-CoV-2 can occur via contact with infected people and their immediate environment. ${ }^{66}$ Therefore, hand hygiene is considered an important component of infection control when caring for patients with COVID-19. In the setting of COVID-19, the WHO recommends cleaning hands with soap and water or an alcohol-based hand sanitizer containing at least $70 \%$ alcohol. ${ }^{67}$ They recommend alcohol-based hand sanitizer use for 20-30 seconds, or, if hands are visibly dirty, then with soap and water for 40-60 seconds. ${ }^{67}$

Search results. We searched PubMed using the terms "hand hygiene," "alcohol-based hand rub/sanitiser," "COVID19," and "coronavirus" as free text, in different combinations, as of July 5, 2020. We also searched WHO documents. We identified one study that met the search criteria.

Evidence. A laboratory-based study showed that SARSCoV-2 was inactivated by WHO-recommended formulations of alcohol-based hand sanitizer, reducing viral titers to the background level within 30 seconds. ${ }^{68}$ There are two WHOrecommended formulations, one containing $80 \%$ ethanol (vol/ vol) and the other containing $75 \%$ isopropyl alcohol ( $\mathrm{vol} / \mathrm{vol})$, and both were shown to be effective. It also showed that ethanol and 2-propanol were effective at inactivating the virus at a concentration $\geq 30 \%$. Of note, the study allowed a full 30 seconds before testing for viral inactivation. Hand hygiene with alcohol-based hand sanitizer is not always carried out for this duration before touching a patient, and it is not possible to conclude if a shorter duration is sufficient.

There were no studies looking at the effectiveness of soap in inactivating SARS-CoV-2. However, previous studies have shown it to be effective at inactivating other enveloped viruses because of the oily surface membrane that is dissolved by soap. ${ }^{69}$ Handwashing also removes pathogens through mechanical action. ${ }^{70}$ 
Where soap and alcohol-based hand sanitizer are not available, the $\mathrm{WHO}$ suggests that using $0.1 \%$ chlorinated water is an option but is not recommended because of the increased risk of dermatitis leading to infections. ${ }^{67}$

Availability, feasibility, affordability, and safety. In LMICs, there are multiple challenges in the implementation of proper hand hygiene. These include an inadequate supply of consumables, including alcohol-based hand sanitizer, soap and paper towels, an unreliable supply of running water, and insufficient washbasins in health facilities. ${ }^{70}$ High patient-tostaff ratios also place additional pressure on adherence to good hand hygiene practices.

Alcohol-based hand sanitizer is expensive relative to soap, so this option may not be readily affordable in all settings. However, the local production of alcohol-based hand sanitizer to the WHO specifications is cost-effective and straight forward, and the efficacy of the local formulations is comparable with commercial ones. ${ }^{71}$ Where alcohol-based hand sanitizer is not readily available, local production is encouraged.

Recommendation and suggestions.

1. When caring for patients with COVID-19, we recommend the use of WHO-approved alcohol-based hand sanitizer for a full 30 seconds, with a sufficient volume to ensure complete hand coverage, before and after each patient contact (strong recommendation and moderate quality of evidence).

2. If WHO-approved alcohol-based hand sanitizer is not available, or when hands are visibly dirty, we recommend washing hands with soap and water for 40-60 seconds, before and after each patient contact (strong recommendation and moderate quality of evidence).

3. We suggest that alcohol-based hand sanitizer be locally produced following the WHO specifications where commercial formulations are not available (best practice statement).

Question 5: Can natural ventilation be used in lieu of mechanical environmental ventilation to carry out care involving aerosol-generating procedures for patients with COVID-19 in LMICs? Rationale. The aim of environmental ventilation in hospitals is to reduce the transmission of airborne infection to staff and other patients by diluting and removing potential pathogens. There is mounting evidence that COVID-19 can be transmitted via airborne particles produced not only during aerosol-generating procedures but also during coughing, speaking, or even breathing. ${ }^{12}$

The recommended standard for mechanical environmental ventilation where aerosol-generating procedures are being performed is to use a negative pressure room with a minimum of 12 air changes per hour. ${ }^{72}$ However, many healthcare facilities do not have negative pressure rooms so use natural ventilation instead. This approach uses airflow generated naturally by wind and temperature differentials to achieve ventilation. ${ }^{73}$ Factors that increase the rate of airflow include opening windows, doors, and other vents, as well as local geography and design features of the building itself.

Search results. We searched MEDLINE using the terms "natural ventilation," "COVID-19," "SARS," "MERS," and "environmental infection control" as free text, in different combinations, on July 1,2020 . There were no trials that compared natural versus mechanical air ventilation in patients with COVID-19. The search identified one observational study that discussed natural ventilation in the context of COVID-19, originating from China. ${ }^{74}$
Four field measurement studies were identified that compared natural versus mechanical air ventilation, two from different HICs and two from Peru, an upper middle-income country. ${ }^{75-78}$ Two observational studies from the SARS outbreak were also reviewed, whereas simulation studies conducted in test-chamber environments were not. ${ }^{10,79,80}$

Two systematic reviews were conducted in 2007 and 2008 and a narrative review from 2015 were identified as partially relevant to the research question, all of which included some studies that were conducted in LMICs. ${ }^{73,81,82}$ The 2009, WHO guideline for Natural Ventilation for Infection Control in Health-Care Settings provides a comprehensive review of the topic. $^{73}$ The evidence that is available is predominantly focused on measurements of airflow, rather than patientorientated outcomes.

Evidence. A study exploring the aerodynamics of COVID-19 transmission described the measurement of the concentrations of aerosolized SARS-CoV-2 RNA in air specimens collected around two hospitals in Wuhan, China. ${ }^{74}$ Although there was no evidence that the air specimens contained viable, infectious virus (the specimens were not cultured), there were lower levels of viral RNA in the "well-ventilated or open public venues" than the more crowded and less wellventilated spaces.

Poor ventilation was also postulated to play a role in some of the large SARS CoV-1 outbreaks in health facilities. ${ }^{79,80}$ An observational study carried out on four wards where SARS patients were receiving care noted that wards with a larger window area-to-room volume ratio were associated with a lower rate of healthcare worker infection. ${ }^{79}$ This was a small study with multiple potential confounders, but the authors concluded that better ventilation may have contributed to the lower rates of nosocomial infection.

The link between air ventilation of hospital facilities and transmission of respiratory pathogens more broadly was the subject of a 2008 systematic review conducted by the team writing the $\mathrm{WHO}$ guidelines on natural ventilation. ${ }^{73}$ The authors concluded that a "lack of ventilation or low ventilation rates are associated with increased infection rates or outbreaks of airborne diseases and high ventilation rates could decrease the risk of infection." They made a conditional recommendation that natural ventilation should provide $160 \mathrm{~L} / \mathrm{s} /$ patient as the absolute ventilation rate per patient but noted that the true minimum ventilation requirements to prevent the spread of airborne infection were (and remain) unknown.

Four studies were identified that measured the rates of air exchange and absolute ventilation in naturally ventilated hospital buildings and compared it with calculated rates of mechanically ventilated facilities. ${ }^{75-78}$ All the studies confirmed that natural ventilation could produce high rates of air exchange, often well above the recommended standard for mechanical air ventilation. However, it should be emphasized that the testing was largely carried out in buildings that had been purpose built or specifically adapted to promote airflow. The results also demonstrated that the measured airflow was dependent on the prevailing weather conditions, was not uniform throughout the room, and could drop below the recommended standard.

Availability, feasibility, affordability, and safety. Rooms with good natural ventilation are often readily available or can be created with minor adjustments to existing structures at minimal cost. ${ }^{76}$ Possible adjustments that may improve 
natural ventilation include the creation of new windows or air vents or alterations to open previously sealed windows. ${ }^{73}$ Alterations to the roof, including the addition of a whirligig roof vent or open skylights, can also increase ventilation (Figure 1). It is important to emphasize to patients and staff that the windows need to remain open for the natural ventilation to be effective.

By comparison, mechanical environmental ventilation systems are expensive to install and to run. They require ongoing maintenance, a supply of spare parts, and careful monitoring to ensure they remain functional. ${ }^{80}$

It is possible to achieve protective levels of natural ventilation even at relatively low wind speeds, but there are still times when the prevailing weather conditions will not generate the necessary rates of airflow. ${ }^{75-78}$ Furthermore, natural ventilation does not maintain a consistent airflow direction.

In facilities where adequate natural ventilation cannot be achieved, a solution that is more affordable than the installation of a fully mechanized ventilation system is to install "exhaust fans," positioned at the point where the airflow exits the building, to create a hybrid system. Hybrid systems have been shown to work in situations where natural ventilation is insufficient but need engineering input and careful installation. ${ }^{73,77}$ Portable air cleaners are another option to enhance removal of infectious particles from the air but are expensive and not yet widely available in many LMICs. ${ }^{83}$

Ceiling fans or pedestal fans mix the air in a room, rather than refresh it and should not be considered a substitute for exhaust fans as a measure to improve ventilation. ${ }^{83}$ Similarly, "split air system" air-conditioning units, which are the most common type of air-conditioning unit in many LMICs, also recirculate indoor air and do not improve the fresh airflow into a room (Figure 1). ${ }^{83}$ Although both fans and air- conditioning units may helpfully decrease the risk of stagnant pockets of air within a room, there is a concern that they may spread virus-containing particles further. ${ }^{84}$ This presents a challenge, given the need to maintain temperature control for patients and staff. We were not able to find any studies or guidance relating to the use of these devices in hospitals in the context of COVID-19. Spread of virus is less of a concern for patients in individual rooms or on wards of confirmed COVID-19 patients, although the additional risk to staff entering these spaces is unknown.

One proposed option would be to switch the fan or airconditioning off while staff are inside the room. This is more feasible in some situations than others. If air-conditioning units are being used, it is important to emphasize to staff that windows need to be left open while they are in operation, although it will decrease their efficiency.

Another safety concern is that the ward windows should not open onto a crowded public thoroughfare, although it is likely that pathogens will be rapidly dispersed once outside. A final consideration is that many settings do not have the equipment necessary to formally test the levels of airflow being generated to ensure that a safe level of airflow is being achieved. The best solution in this situation is to measure the levels of carbon dioxide $\left(\mathrm{CO}_{2}\right)$ in the room as a proxy indicator of ventilation. Nondispersive infrared $\mathrm{CO}_{2}$ analyzers generally cost between $\$ 100$ and $\$ 200$ and are increasingly easy to procure. ${ }^{85}$ This is an evolving area of research without a consensus on what the target $\mathrm{CO}_{2}$ level should be in healthcare settings, but preliminary guidance for non-healthcare settings suggests to aim for a $\mathrm{CO}_{2}$ level at least below 800 parts per million. ${ }^{85-87}$

In the absence of a $\mathrm{CO}_{2}$ analyzer, the pragmatic solution in this situation is to take all reasonable measures to optimize the natural ventilation, despite being unable to measure their precise impact. These measures are described in more detail
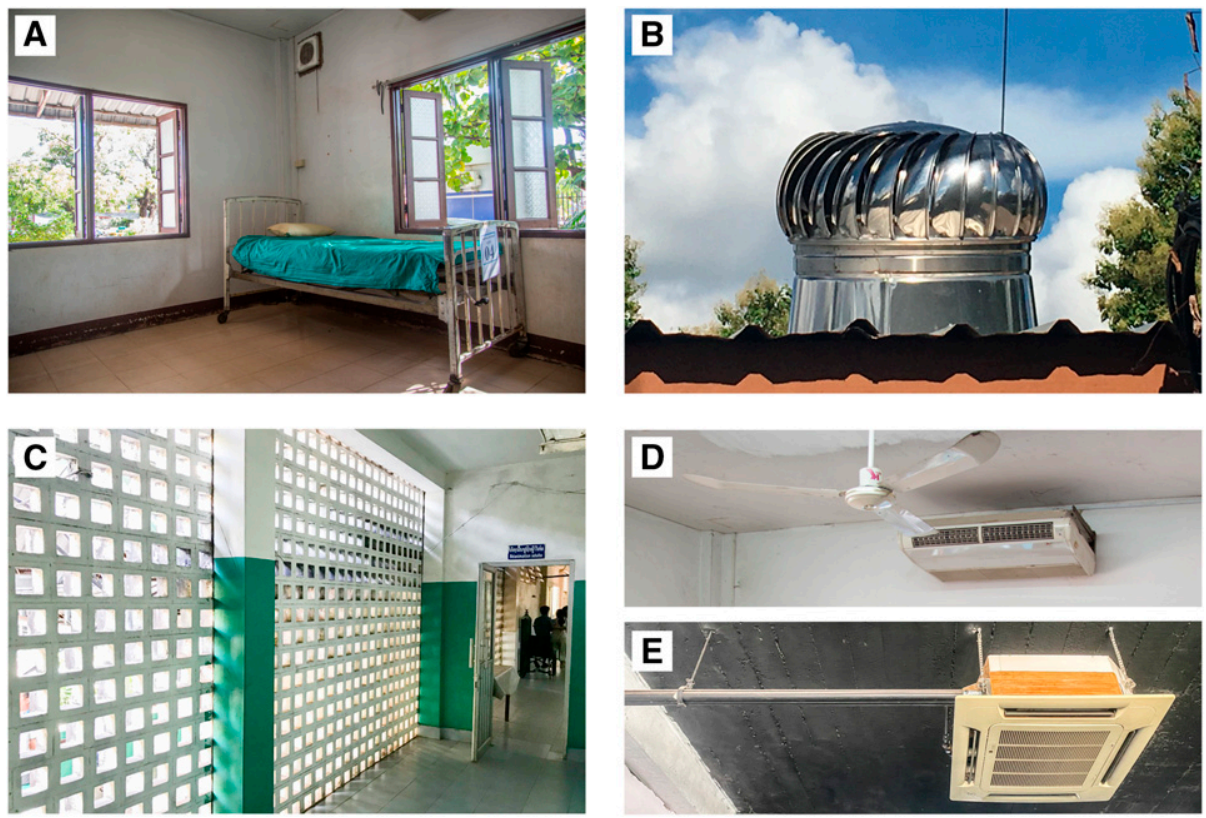

FIGURE 1. Environmental ventilation (photos by Dr. Rebecca Inglis). (A) Large, open windows on two different walls improve natural ventilation. The wall-mounted extractor fan should be set to blow outward not inward. (B) A whirligig roof ventilator. The ventilator spins in the wind as warm air rises. The spinning draws out air from inside the building, improving ventilation. (C) Vented wall to increase airflow in a hospital corridor. (D) + (E) Two examples of split air system air-conditioning units in common usage and a ceiling fan. All three recirculate air within a room, rather than increasing the flow of fresh air from outside. 
elsewhere. ${ }^{73}$ There are rules of thumb that can be used to help. For example, one such rule states that rooms with windows on only one side can be adequately ventilated if the depth of the room is less than twice the height. ${ }^{83}$ The Indian national guideline on airborne infection control suggests openings should constitute greater than $20 \%$ of the floor area, and there should be openings on two sides of the room, preferably on opposite sides. ${ }^{88}$ In summary, natural ventilation is widely available and can be feasible, affordable, and safe but requires care and planning to maximize its effectiveness.

Recommendations.

1. Where mechanical air ventilation is not available, we recommend that natural ventilation can be an acceptable alternative when carrying out aerosol-generating procedures for patients with COVID-19, provided flow rates of at least $160 \mathrm{~L} /$ second/ patient or 12 air changes per hour are achieved. Where aerosolgenerating procedures are not performed, $60 \mathrm{~L} /$ second/patient or six air changes per hour is sufficient (strong recommendation and moderate quality of evidence).

2. Where it is not possible to formally measure airflow, we recommend the use of $\mathrm{a} \mathrm{CO}_{2}$ analyzer to measure indoor $\mathrm{CO}_{2}$ as a proxy indicator of ventilation (strong recommendation and moderate quality of evidence).

3. We recommend that the room where aerosol-generating procedures are performed be selected or modified to include some or all of the following design features, using the design principles from the WHO Natural Ventilation guidelines (strong recommendation and moderate quality of evidence).

a. Large, open windows

b. Windows on more than one wall; opposite walls if possible

c. High ceilings

d. Additional air vents; open skylights or whirligig roof ventilator (strong recommendation and moderate quality of evidence).

4. In a facility with natural ventilation, we recommend that the windows and other ventilation vents be left open at all times to allow airflow. The door to the rest of the hospital should be left shut (strong recommendation and moderate quality of evidence).

5. In a setting with insufficient natural ventilation, we recommend that a hybrid or mixed-mode system of air ventilation be created by installing exhaust fans in conjunction with the natural ventilation measures (strong recommendation and moderate quality of evidence).

6. We recommend that measures to improve natural ventilation be taken in all areas where COVID-19 patients are being cared for, whether aerosol-generating procedures are being carried out or not (strong recommendation and low quality of evidence).

Received September 2, 2020. Accepted for publication December 6, 2020.

Published online December 22, 2020.

Note: The Appendix can be found at www.ajtmh.org.

Financial support: Open access fees for this article and all others in this issue were supported by the Wellcome Trust of Great Britain.

Authors' addresses: Rebecca Inglis, Lao-Oxford-Mahosot HospitalWellcome Trust Research Unit (LOMWRU), Mahosot Hospital, University of Oxford, Vientiane, Lao People's Democratic Republic, E-mail: rebecca.i@tropmedres.ac. Lia Barros, Division of Cardiology, University of Washington, Seattle, WA, E-mail: Ibarros@uw.edu.
William Checkley, Division of Pulmonary and Critical Care, Department of Medicine, School of Medicine, Johns Hopkins University, Baltimore, MD, and Center for Global Non-Communicable Disease Research and Training, School of Medicine, Johns Hopkins University, Baltimore, MD, E-mail: wcheckl1@jhmi.edu. Elif A. Cizmeci, Interdepartmental Division of Critical Care Medicine, Sunnybrook Health Sciences Centre, University of Toronto, Toronto, Canada, E-mail: eacizmeci@gmail.com. Faith Lelei-Mailu, Department of Quality Health and Safety, AIC Kijabe Hospital, Kijabe, Kenya, E-mail: faithlelei@gmail.com. Rajyabardhan Pattnaik, Division of Critical Care Medicine, Ispat General Hospital, Rourkela, India, E-mail: rajyapattnaik@yahoo.co.in. Alfred Papali, Division of Pulmonary and Critical Care Medicine, Atrium Health, Charlotte, North Carolina, E-mail: alfred.papali@atriumhealth.org. Marcus J. Schultz, Department of Intensive Care, Amsterdam University Medical Centers, Amsterdam, The Netherlands, Department of Clinical Tropical Medicine, Mahidol University, Bangkok, Thailand, and Mahidol-Oxford Tropical Medicine Research Unit (MORU), Mahidol University, Bangkok, Thailand, E-mail: marcus.j.schultz@gmail.com. Juliana C. Ferreira, Divisao de Pneumologia, Instituto do Coracao, Hospital das Clinicas HCFMUSP, Faculdade de Medicina, Universidade de Sao Paulo, Sao Paulo, Brazil, E-mail: juliana.ferreira@hc.fm.usp.br.

This is an open-access article distributed under the terms of the Creative Commons Attribution (CC-BY) License, which permits unrestricted use, distribution, and reproduction in any medium, provided the original author and source are credited.

\section{GROUP MEMBERS OF THE "COVID-LMIC TASK FORCE”}

Heads: Alfred Papali (Atrium Health, Charlotte, NC) and Marcus Schultz (Mahidol University, Bangkok, Thailand; University of Oxford, Oxford, United Kingdom; Amsterdam University Medical Centers, location "AMC", Amsterdam, The Netherlands).

Advisors: Neill K. J. Adhikari (Interdepartmental Division of Critical Care Medicine, University of Toronto, Toronto, Canada); Emilie J. Calvello Hynes (University of Colorado School of Medicine, Department of Emergency Medicine, Denver, CO); Martin Dünser (Kepler University Hospital and Johannes Kepler University Linz, Linz, Austria) and Mervyn Mer (University of the Witwatersrand, Johannesburg, South Africa).

Subgroup members, in alphabetical order: Andrew Achilleos (Sunnybrook Health Sciences Centre, Toronto, Canada); Hanan Y. Ahmed (Department of Internal Medicine, College of Health Sciences, Addis Ababa University, Addis Ababa, Ethiopia). Kevan M. Akrami (Universidade Federal da Bahia, Salvador, Brazil; University of California San Diego, San Diego, CA); Lia M. Barros (University of Washington, Seattle, WA); B. Jason Brotherton (AIC Kijabe Hospital, Kijabe, Kenya); Sopheakmoniroth Chea (Calmette Hospital, Phnom Penh, Cambodia); William Checkley (Division of Pulmonary and Critical Care, School of Medicine, Johns Hopkins University; Baltimore, MD); Elif A. Cizmeci (Interdepartmental Division of Critical Care Medicine, Sunnybrook Health Sciences Centre, University of Toronto, Toronto, Canada); Natalie Cobb (University of Washington, Seattle, WA); Finot Debebe (Department of Emergency Medicine and Critical Care, Addis Ababa University School of Medicine, Addis Ababa, Ethiopia); Juliana C Ferreira (University of São Paulo, São Paulo, Brazil); Gabriela Galli (University of Pittsburgh School of Medicine, Pittsburgh, PA); Tewodros Haile (Department of Internal Medicine, College of Health Sciences, Addis Ababa University); Bhakti Hansoti (Department of Emergency Medicine, Johns Hopkins University School of Medicine, Baltimore, MA); Madiha Hashmi (Ziauddin University, Karachi, Pakistan); Rebecca Inglis (Lao-Oxford-Mahosot Hospital-Wellcome Trust Research Unit (LOMWRU), Mahosot Hospital, Vientiane, Lao People's Democratic Republic and Department of Intensive Care, Oxford University Hospital Trust, Oxford, United Kingdom); Burton W. Lee (Critical Care Department, NIH, Bethesda, MD; Division of Pulmonary, Allergy and Critical Care, University of Pittsburgh School of Medicine, Pittsburgh, PA); Faith Lelei (AIC Kijabe Hospital, Kijabe, Kenya); Ganbold Lundeg (Mongolian National University of Medical Sciences, Ulan Bator, Mongolia); David Misango (The Aga Khan University, Nairobi, Kenya); Ary Serpa Neto (Department of Critical Care Medicine, Hospital Israelita Albert Einstein, São Paulo, Brazil; Australian and New Zealand Intensive Care Research Centre (ANZIC-RC), Monash University, Melbourne, Australia; 
Department of Intensive Care, Amsterdam University Medical Centers, location "AMC," University of Amsterdam, Amsterdam, The Netherlands); Alfred Papali (Atrium Health, Charlotte, NC); Casey Park (Interdepartmental Division of Critical Care Medicine, Sunnybrook Health Sciences Centre, University of Toronto, Toronto, Canada); Rajyabardhan Pattnaik (Ispat General Hospital, Rourkela, India); Jennifer L. Pigoga (Division of Emergency Medicine, University of South Africa, Cape Town, South Africa); Luigi Pisani (Department of Anesthesia and Intensive Care, Miulli Regional Hospital, Acquaviva delle Fonti, Italy; Doctors with Africa - CUAMM, Padova, Italy; Mahidol-Oxford Tropical Medicine Research Unit (MORU), Mahidol University, Bangkok, Thailand); Elisabeth D. Riviello (Division of Pulmonary, Critical Care, and Sleep Medicine, Beth Israel Deaconess Medical Center and Harvard Medical School, Boston, MA); Kristina E. Rudd (University of Pittsburgh School of Medicine, Pittsburgh, PA); Marcus Schultz (Mahidol University, Bangkok, Thailand; University of Oxford, Oxford, United Kingdom; Amsterdam University Medical Centers, location "AMC," Amsterdam, The Netherlands); Varun U. Shetty (University of Pittsburgh Medical Center, Pittsburgh, PA); Gentle S. Shrestha (Tribhuvan University Teaching Hospital, Kathmandu, Nepal); Chaisith Sivakorn (Mahidol University, Salaya, Thailand); Shaurya Taran (Interdepartmental Division of Critical Care Medicine, Sunnybrook Health Sciences Centre, University of Toronto, Toronto, Canada); T. Eoin West (University of Washington, Seattle, WA).

Group members of the subgroup "Safety": Rebecca Inglis (LaoOxford-Mahosot Hospital-Wellcome Trust Research Unit (LOMWRU), Mahosot Hospital, Vientiane, Lao People's Democratic Republic and Department of Intensive Care, Oxford University Hospital Trust, Oxford, United Kingdom); William Checkley (Division of Pulmonary and Critical Care, School of Medicine, Johns Hopkins University; Baltimore, MD), Elif A. Cizmeci (Interdepartmental Division of Critical Care Medicine, Sunnybrook Health Sciences Centre, University of Toronto, Toronto, Canada); Lia M. Barros (University of Washington, Seattle, WA); Rajyabardhan Pattnaik (Ispat General Hospital, Rourkela, India); Faith Lelei (AIC Kijabe Hospital, Kijabe, Kenya); Juliana C Ferreira (University of São Paulo, São Paulo, Brazil); Marcus Schultz (Mahidol University, Bangkok, Thailand; University of Oxford, Oxford, United Kingdom; Amsterdam University Medical Centers, location "AMC," Amsterdam, The Netherlands), and Alfred Papali (Atrium Health, Charlotte, NC).

\section{REFERENCES}

1. Xie $\mathrm{M}, \mathrm{Chen} \mathrm{Q}, 2020$. Insight into 2019 novel coronavirus - an updated interim review and lessons from SARS-CoV and MERS-CoV. Int J Infect Dis 94: 119-124.

2. Koh WC et al., 2020. What do we know about SARS-CoV-2 transmission? A systematic review and meta-analysis of the secondary attack rate and associated risk factors. PLoS One 15: e0240205.

3. Lai $X$ et al., 2020. Coronavirus disease 2019 (COVID-2019) infection among health care workers and implications for prevention measures in a tertiary hospital in Wuhan, China. JAMA Netw Open 3: e209666.

4. Lessells R, Moosa MY, De Oliveira T, 2020. St Augustines Hospital Outbreak Investigation. Final Report. Available at: https:// www.krisp.org.za/news. php?id=421 (pdf). Accessed December 162020.

5. Remuzzi A, Remuzzi G, 2020. COVID-19 and Italy: what next? Lancet 395: 1225-1228.

6. Livingston E, Bucher K, 2020. Coronavirus disease 2019 (COVID19) in Italy. JAMA 323: 1335.

7. Zhan M, Qin Y, Xue X, Zhu S, 2020. Death from COVID-19 of 23 health care workers in China. N Engl J Med 382: 2265-2267.

8. Chersich MF et al., 2020. COVID-19 in Africa: care and protection for frontline healthcare workers. Glob Health 16: 46.

9. Delgado D, Quintana FW, Perez G, Liprandi AS, Ponte-Negretti C, Mendoza I, Baranchuk A, 2020. Personal safety during the COVID-19 pandemic: realities and perspectives of healthcare workers in Latin America. Int J Environ Res Public Health 17: 2798.

10. Jones RM, 2020. Relative contributions of transmission routes for COVID-19 among healthcare personnel providing patient care. J Occup Environ Hyg 17: 408-415.
11. Zhang Z, Liu S, Xiang M, Li S, Zhao D, Huang C, Chen S, 2020. Protecting healthcare personnel from 2019-nCoV infection risks: lessons and suggestions. Front Med 14: 2019-2021.

12. Zhang XS, Duchaine C, 2020. SARS-CoV-2 and health care worker protection in low-risk settings: a review of modes of transmission and a novel airborne model involving inhalable particles. Clin Microbiol Rev 34: e00184-20.

13. World Health Organization, 2020. Rational Use of Personal Protective Equipment for Coronavirus Disease (COVID-19) and Considerations during Severe Shortages. Geneva, Switzerland: WHO.

14. Liu $\mathrm{M}$ et al., 2020. Use of personal protective equipment against coronavirus disease 2019 by healthcare professionals in Wuhan, China: cross sectional study. BMJ 369: m2195.

15. CDC, 2020. Interim Infection Prevention and Control Recommendations for Healthcare Personnel During the Coronavirus Disease 2019 (COVID-19) Pandemic. Available at: https:// www.cdc.gov/coronavirus/2019-ncov/hcp/infection-controlrecommendations.html. Accessed September 152020.

16. Nolan JP et al., 2020. European resuscitation council COVID-19 guidelines executive summary. Resuscitation 153: 45-55.

17. Public Health England, 2020. COVID-19 Personal Protective Equipment. Available at: https://www.gov.uk/government/ publications/wuhan-novel-coronavirus-infection-preventionand-control/covid-19-personal-protective-equipment-ppe. Accessed July 21, 2020.

18. Nguyen LH et al., 2020. Risk of COVID-19 among frontline healthcare workers and the general community: a prospective cohort study. Lancet Public Health 5: E475-E483.

19. Verbeek J, Rajamaki B, ljaz S, Sauni R, Toomey E, Blackwood B, Tikka C, Ruotsalainen J, Kilinc Balci F, 2020. Personal protective equipment for preventing highly infectious diseases due to exposure to contaminated body fluids in healthcare sta (Review). Cochrane Database Syst Rev Libr 5: CD011621.

20. Chu DK, Akl EA, Duda S, Solo K, Yaacoub S, Schünemann HJ, Urgent CS, 2020. Physical distancing, face masks, and eye protection to prevent person-to-person transmission of SARSCoV-2 and COVID-19: a systematic review and meta-analysis. Lancet 395: 1973-1987.

21. Klompas M, Baker M, Rhee C, 2020. Airborne transmission of SARS-CoV-2 theoretical considerations and available evidence. J Am Med Assoc 324: 441-442.

22. Smith JD, Macdougall CC, Johnstone J, Copes RA, Schwartz B, Garber GE, 2016. Effectiveness of N95 respirators versus surgical masks in protecting health care workers from acute respiratory infection: a systematic review and meta-analysis. Can Med Assoc J 188: 567-574.

23. Long Y, Hu T, Liu L, Chen R, Guo Q, Yang L, Cheng Y, Huang J, Du $\mathrm{L}, 2020$. Effectiveness of $\mathrm{N} 95$ respirators versus surgical masks against influenza: a systematic review and meta-analysis. J Evid Based Med 13: 93-101.

24. Radonovich L Jr et al., 2019. N95 respirators vs medical masks for preventing influenza among health care personnel a randomized clinical trial. JAMA 322: 824-833.

25. Rengasamy S, Eimer B, Shaffer RE, 2010. Simple respiratory protection - evaluation of the filtration performance of cloth masks and common fabric materials against $20-1000 \mathrm{~nm}$ size particles. Ann Occup Hyg 54: 789-798.

26. Díaz-Guio DA, Ricardo-Zapata A, Ospina-Velez J, GómezCandamil G, Mora-Martinez S, Rodriguez-Morales AJ, 2020. Cognitive load and performance of health care professionals in donning and doffing PPE before and after a simulation-based educational intervention and its implications during the COVID19 pandemic for biosafety. Infez Med 28: 111-117.

27. Bonar H, Filip A, 2020. RESEARCH BRIEF: COVID-19-Related Trafficking of Medical Products as a Threat to Public Health. Available at: https://www.unodc.org/documents/data-andanalysis/covid/COVID-19_research_brief_trafficking_medical_ products.pdf. Accessed December 162020.

28. European Safety Federation, 2020. COVID-19-Suspicious Certificates for PPE. Available at: https://www.eu-esf.org/covid-19/4513-covid19-suspicious-certificates-for-ppe. Accessed July 21, 2020.

29. Rana S, 2020. Rise of Counterfeit PPE in India Amid COVID-19. ICLG.com. Available at: https://iclg.com/briefing/13315-riseof-counterfeit-ppe-in-india-amid-covid-19. Accessed December 162020. 
30. World Health Organization, 2020. WHO Disease Commodity Package - COVID-19. Geneva, Switzerland: WHO. WHO/2019nCoV/DCPv3/2020.4. Available at: https://apps.who.int/iris/ bitstream/handle/10665/331434/WHO-2019-nCoV-DCPv32020.4-eng.pdf. Accessed July 21, 2020.

31. British Safety Industry Federation, 2020. Counterfeit PPE Checklist. Available at: https://bda.org/advice/Coronavirus/ Documents/Counterfeit-ppe-checklist.pdf. Accessed July 21, 2020.

32. The Chartered Society for Worker Health Protection, 2020. Spotting a Fake Respirator. Available at: https://bda.org/ advice/Coronavirus/Documents/spotting-fake-face-masks. pdf. Accessed July 21, 2020.

33. Rubio-Romero JC, Pardo-Ferreira MDC, Torrecilla-García JA, Calero-Castro S, 2020. Disposable masks: disinfection and sterilization for reuse, and non-certified manufacturing, in the face of shortages during the COVID-19 pandemic. Saf Sci 129: 104830.

34. Zorko DJ, Gertsman S, O'Hearn K, Timmerman N, Ambu-Ali N, Dinh T, Sampson M, Sikora L, McNally JD, Choong K, 2020. Decontamination interventions for the reuse of surgical mask personal protective equipment: a systematic review. J Hosp Infect 106: 283-294.

35. Toomey E et al., 2020. Extended use or reuse of single-use surgical masks and filtering face-piece respirators during the coronavirus disease 2019 (COVID-19) pandemic: A rapid systematic review. Infect Control Hosp Epidemiol. doi:10.1017/ ice.2020.1243.

36. Macintyre CR, Seale H, Dung TC, Hien NT, Nga PT, Chughtai AA, Rahman B, Dwyer DE, Wang Q, 2015. A cluster randomised trial of cloth masks compared with medical masks in healthcare workers. Br Med J Open 5: e006577.

37. Vuma CD, Manganyi J, Wilson K, Rees D, 2019. The effect on fit of multiple consecutive donning and doffing of N95 filtering facepiece respirators. Ann Work Expo Heal 63: 930-936.

38. Degesys NF, Wang RC, Kwan E, Fahimi J, Noble JA, Raven MC, 2020. Correlation between N95 extended use and reuse and fit failure in an emergency department. JAMA 324: 94-96.

39. Fisher EM, Shaffer RE, 2014. Considerations for recommending extended use and limited reuse of filtering facepiece respirators in health care settings and limited reuse recommendations. J Occup Environ Hyg 11: 115-128.

40. Bergman MS, Viscusi DJ, Zhuang Z, Palmiero AJ, Powell JB, Shaffer RE, 2012. Impact of multiple consecutive donnings on filtering facepiece respirator fit. $A m \mathrm{~J}$ Infect Control 40: 375-380.

41. CDC, 2020. The National Institute for Occupational Safety and Health Recommended Guidance for Extended Use and Limited Reuse of N95 Filtering Facepiece Respirators in Healthcare Settings. Available at: https://www.cdc.gov/niosh/topics/ hcwcontrols/recommendedguidanceextuse.html. Accessed June 6, 2020.

42. CDC, 2020. Decontamination and Reuse of Filtering Facepiece Respirators. Available at: https://www.cdc.gov/coronavirus/ 2019-ncov/hcp/ppe-strategy/decontamination-reuse-respirators. html. Accessed June 6, 2020.

43. N95DECON, 2020. A Scientific Consortium for Data-Driven Study of N95 Filtering Facepiece Respirator Decontamination. Available at: www.n95decon.org/. Accessed December 16, 2020.

44. N95DECON, 2020. Technical Report for Room Temperature Storage of N95 FFR for Bioburden Reduction and Reuse. Available at: https://www.n95decon.org/files/time-technicalreport. Accessed December 16, 2020.

45. Gao P, Horvatin M, Niezgoda G, Weible R, 2016. Effect of multiple alcohol-based hand rub applications on the tensile properties of thirteen brands of medical exam nitrile and latex gloves. J Occup Environ Hyg 13: 905-914.

46. Kimberly-Clark, 2009. KIMBERLY-CLARK* Nitrile Gloves Chemical Resistance Guide. Available at: https://www.kimtech.com/ nitrilechemicalresistanceguide/K2365_09_01_SN\%20Chem\% 20Guide_v10.pdf. Accessed December 16, 2020.

47. CDC, 2020. Coronavirus Disease 2019 (COVID-19) Strategies for Optimizing the Supply of Disposable Medical Gloves Continue Providing Patient Care without Any Change in Daily Use of Gloves Past Their Manufacturer-Designated Shelf Life for
Training. Available at: https://www.cdc.gov/coronavirus/2019ncov/hcp/ppe-strategy/gloves.html. Accessed June 6, 2020.

48. Godoy LRG, Jones AE, Anderson TN, Fisher CL, Seeley KML, Beeson EA, Zane HK, Peterson JW, Sullivan PD, 2020. Facial protection for healthcare workers during pandemics: a scoping review. BMJ Glob Health 5: 1 e002553.

49. Roberge RJ, 2016. Face shields for infection control: a review. $J$ Occup Environ Hyg 13: 239-246.

50. Roberge RJ, 2008. Effect of surgical masks worn concurrently over N95 filtering facepiece respirators: extended service life versus increased user burden. J Public Heal Manag Pract 14: E19-26.

51. Lindsley WG, Noti JD, Blachere FM, Jonathan V, Beezhold DH, Virginia W, 2014. Efficacy of face shields against cough aerosol droplets from a cough simulator. $J$ Occup Environ Hyg 11: 509-518.

52. Perencevich EN, Diekema DJ, Edmond MB, 2020. Moving personal protective equipment into the community face shields and containment of COVID-19. JAMA 323: 2252-2253.

53. Kilinc FS, 2016. A review of isolation gowns in healthcare: fabric and gown properties. J Eng Fiber Fabr 10: 180-190.

54. CDC, 2020. Strategies for Optimizing the Supply of Isolation Gowns. Available at: https://www.cdc.gov/coronavirus/2019ncov/hcp/ppe-strategy/isolation-gowns.html. Accessed December 16, 2020.

55. CDC, 2020. Operational Considerations for Personal Protective Equipment in the Context of Global Supply Shortages for Coronavirus Disease 2019 (COVID-19) Pandemic. Available at: https://www.cdc.gov/coronavirus/2019-ncov/hcp/non-ussettings/emergency-considerations-ppe.html. Accessed December 16, 2020.

56. Ağalar C, Engin DÖ, 2020. Protective measures for COVID-19 for healthcare providers and laboratory personnel. Turkish $\mathrm{J}$ Med Sci 50: 578-584.

57. Azap A, Erdinç FŞ, 2020. Medical mask or N95 respirator: when and how to use? Turkish J Med Sci 50: 633-637.

58. Forrester JD, Nassar AK, Hawn MT, Maggio PM, 2020. Precautions for operating room team members during the COVID-19 pandemic. J Am Coll Surg 230: 1098-1101.

59. Shankar A, Saini D, Roy S, Jarrahi AM, Chakraborty A, Bharati SJ, Taghizadeh-hesary F, 2020. Cancer care delivery challenges amidst coronavirus disease - 19 (COVID-19) outbreak: specific precautions for cancer patients and cancer care providers to prevent spread. Asian Pac J Cancer Prev 21: 569-573.

60. Skulstad H et al., 2020. COVID-19 pandemic and cardiac imaging: EACVI recommendations on precautions, indications, prioritization, and protection for patients and healthcare personnel. Eur Heart J Cardiovasc Imaging 21: 592-598.

61. Heinzerling A, Stuckey MJ, Scheuer T, Xu K, Perkins KM, Resseger H, 2020. Transmission of COVID-19 to health care personnel during exposures to a hospitalized patient - Solano County, California, February 2020. MMWR Morb Mortal Wkly Rep 69: 472-476.

62. Lockhart SL, Duggan FLV, Wax FRS, 2020. Personal protective equipment (PPE) for both anesthesiologists and other airway managers: principles and practice during the COVID-19 pandemic. Can J Anesth Can d'anesthésie 67: 1005-1015.

63. Moro M, Pietro G, Capraro M, Biancardi A, Nizzero P, Signorelli C, Odone A, 2020. 2019-novel coronavirus survey: knowledge and attitudes of hospital staff of a large Italian teaching hospital. Acta Biomed 91: 29-34.

64. Houghton $\mathrm{C}$ et al., 2020. Barriers and facilitators to healthcare workers' adherence with infection prevention and control (IPC) guidelines for respiratory infectious diseases: a rapid qualitative evidence synthesis. Cochrane Database Syst Rev 4: CD013582.

65. Gosling AF, Bose S, Gomez E, Cook C, Shaefi S, Leibowitz A, 2020. Perioperative considerations for tracheostomies in the era of COVID-19. Anesth Analg 131: 378-386.

66. World Health Organization, 2020. Transmission of SARS-CoV-2: Implications for Infection Prevention Precautions. Geneva, Switzerland: WHO. Available at: https://www.who.int/news-room/ commentaries/detail/transmission-of-sars-cov-2-implications-forinfection-prevention-precautions. Accessed December 16, 2020. 
67. World Health Organization, 2020. Water, Sanitation, Hygiene and Waste Management for the COVID-19 Virus. Geneva, Switzerland: $\mathrm{WHO}$.

68. Kratzel A et al., 2020. Inactivation of severe acute respiratory syndrome coronavirus 2 by WHO-recommended hand rub formulations and alcohols. Emerg Infect Dis 26: 1592-1595.

69. Sickbert-bennett EE, Weber DJ, Gergen-teague MF, Ascp MT, Sobsey MD, Samsa GP, Rutala WA, 2005. Comparative efficacy of hand hygiene agents in the reduction of bacteria and viruses. Am J Infect Control 33: 67-77.

70. World Health Organization, 2009. WHO Guidelineson Hand Hygiene in Health Care: A Summary. Geneva, Switzerland: WHO.

71. World Health Organization, 2010. Guide to Local Production: WHO-Recommended Handrub Formulations. Geneva, Switzerland: $\mathrm{WHO}$.

72. Sehulster LM et al., 2019. Healthcare Infection Control Practices Advisory Committee (HICPAC): Guidelines for Environmental Infection Control in Health-Care Facilities. U.S. Department of Health and Human Services Centers for Disease Control Prevention (CDC) Atlanta, GA 30329. Available at: http://www. cdc.gov/hicpac/pdf/guidelines/eic_in_hcf_03.pdf. Accessed December 16, 2020.

73. Atkinson J, Chartier Y, Lúcia Pessoa-Silva C, Jensen P, Li Y, Seto WH, 2009. Natural Ventilation for Infection Control in Health-Care Settings WHO Library Cataloguing-In-Publication Data: Natural Ventilation for Infection Control in Health-Care Settings. Vol. 1. Available at: https:// www.who.int/water_sanitation_health/publications/natural_ ventilation/en/. Accessed December 16, 2020.

74. Liu Y et al., 2020. Aerodynamic analysis of SARS-CoV-2 in two Wuhan hospitals. Nature 582: 557-560.

75. Escombe AR et al., 2007. Natural ventilation for the prevention of airborne contagion. PLoS Med 4: 309-317.

76. Escombe AR, Ticona E, Chávez-Pérez V, Espinoza M, Moore DAJ, 2019. Improving natural ventilation in hospital waiting and consulting rooms to reduce nosocomial tuberculosis transmission risk in a low resource setting. BMC Infect Dis 19: 88.

77. Qian H, Li Y, Seto WH, Ching P, Ching WH, Sun HQ, 2010. Natural ventilation for reducing airborne infection in hospitals. Build Environ 45: 559-565.

78. Gilkeson CA, Camargo-Valero MA, Pickin LE, Noakes CJ, 2013. Measurement of ventilation and airborne infection risk in large naturally ventilated hospital wards. Build Environ 65: 35-48.

79. Jiang SP et al., 2013. Ventilation of wards and nosocomial outbreak of severe acute respiratory syndrome among healthcare workers. Chin Med J (Engl) 116: 1293-1297.

80. Li Y, Huang X, Yu ITS, Wong TW, Qian H, 2005. Role of air distribution in SARS transmission during the largest nosocomial outbreak in Hong Kong. Indoor Air 15: 83-95.

81. Li Y et al., 2007. Role of ventilation in airborne transmission of infectious agents in the built environment - a multidisciplinary systematic review. Indoor Air 17: 2-18.

82. Shakoor S, Mir F, Zaidi AKM, Zafar A, 2015. Hospital preparedness in community measles outbreaks-challenges and recommendations for low-resource settings. Emerg Health Threats J 8: 24173.

83. Iddon C, Hathaway A, Fitzgerald S, Mills F, Stevens D, Adams G, Day T, 2020. CIBSE COVID-19 Ventilation Guidance Version 2. Available at: https://go.cibse.org///698403/2020-05-13/ 28tz75/698403/76378/CIBSE_Covid_Ventilation_Guidance_ version_2.pdf. Accessed December 16, 2020.

84. Baka A, Cenciarelli O, Kinross P, Penttinen P, Plachouras D, Semenza J, Suetens C, Weist K, 2020. Heating, Ventilation and Air-Conditioning Systems in the Context of COVID-19.
Available at: https://www.ecdc.europa.eu/sites/default/files/ documents/Ventilation-in-the-context-of-COVID-19.pdf. Accessed December 16, 2020.

85. Marr $L$ et al., 2020. FAQs on Protecting Yourself from COVID-19 Aerosol Transmission. Available at: https://tinyurl.com/FAQaerosols.FAQs. Accessed November 7, 2020.

86. Peng Z, Jimenez JL, 2020. Title: exhaled $\mathrm{CO}_{2}$ as COVID-19 infection risk proxy for different indoor environments and activities (Not yet peer reviewed). medRxiv. doi: 10.1101/2020.09.09.20191676.

87. Allen DA et al., 2020. Role of Ventilation in Controlling SARS-CoV2 Transmission, a Report by the Environmental and Modelling Group of the Scientific Advisory Group for Emergencies. London: SAGE. Available at: https://www.gov.uk/government/publications/ emg-role-of-ventilation-in-controlling-sars-cov-2-transmission-30september-2020. Accessed December 16, 2020.

88. Agarwal A, Anand S, Chadha S, Dewan P, Jundal S, Parmar M, Rajasekaran S, Ramachandran R, Solanki R, 2010. Guidelines on Airborne Infection Control in Healthcare and Other Settings. Available at: https://tbcindia.gov.in/showfile.php?lid=2858.

\section{APPENDIX}

Development of recommendations and suggestions. Selection of task force members. The selection of the group members was based on interest in specific aspects of COVID19 and direct experience in low- and middle-income countries (LMICs). Alfred Papali and Marcus Schultz contacted potential team members through email and in person early in the pandemic of COVID-19, and created eight subgroups assigned to separate areas in COVID-19 management: "triage," "safety," "organization," "diagnostics," "acute respiratory failure," "acute kidney injury," "coagulopathy," "therapeutics," "shock," and "support after initial care."

In total, there were 38 Task Force members representing five medical specialties or disciplines (emergency medicine, intensive care, infectious diseases, internal medicine and critical care nursing) from five out of six World Health Organization $(\mathrm{WHO})$ geographic regions. The Task Force consisted of 16 full-time LMIC members, 16 full time high-income country (HIC) members-all with direct LMIC experience-and 6 members with joint LMIC/HIC appointments.

Selection of subgroup members. Rebecca Inglis, Lia Barros, William Checkley, Elif Cizmeci, Faith Lelei-Mailu, Rajyabardhan Pattnaik, Alfred Papali, Marcus J. Schultz, and Juliana $C$ Ferreira were assigned to this subgroup based on their specific expertise and interest in safety of patients and healthcare workers caring for patients with COVID-19.

Meetings. The subgroup worked via electronic-based communications to establish the procedures for the literature review, develop relevant questions, and drafting of tables for evidence analysis. Several electronic-based discussions among the subgroup leaders and members occurred. The first step was to formulate a set of clearly defined questions regarding safety for patients and HCWs caring for patients with suspected or confirmed COVID-19. An initial list of potential questions was

TABLE A1

Quality of evidence

\begin{tabular}{ll}
\hline A & Randomized clinical trials \\
B & Downgraded randomized clinical trial(s) or upgraded observational studies \\
C & Observational studies \\
D & Downgraded observational studies or expert opinions \\
\hline Factors that may decrease strength of evidence include high likelihood of bias; inconsistency of results, including problems with subgroup analyses; indirectness of evidence (other population,
\end{tabular}
intervention, control, outcomes, and comparison); imprecision of findings; and likelihood of reporting bias.

Factors that may increase strength of evidence: large magnitude of effect (direct evidence, relative risk $>2$ with no plausible confounders); very large magnitude of effect with relative risk $>5$; and no threats to validity (by two levels); and dose-response gradient. ${ }^{1}$ 
TABLE A2

Strong vs. weak recommendations*

\begin{tabular}{|c|c|}
\hline What is Considered & How it affects the recommendation \\
\hline High evidence & The higher the quality of evidence, the more likely is a strong recommendation \\
\hline $\begin{array}{l}\text { Certainty about the balance of benefits vs. } \\
\text { harms and burdens }\end{array}$ & $\begin{array}{l}\text { The larger/smaller the difference between the desirable and undesirable consequences and the } \\
\text { certainty around that difference, the more likely is a strong/weak recommendation }\end{array}$ \\
\hline Certainty in or similar values & $\begin{array}{l}\text { The more certainty or similarity in values and preferences, the more likely is a strong } \\
\text { recommendation }\end{array}$ \\
\hline Resource implications & $\begin{array}{l}\text { The lower/higher the cost of an intervention than the alternative, the more likely is a strong/weak } \\
\text { recommendation }\end{array}$ \\
\hline Availability and feasibility in LMICs & The less available, the more likely is a weak recommendation \\
\hline Affordability for LMICs & The less affordable, the more likely is a weak recommendation \\
\hline Safety of the intervention in LMICs & The less safe in an LMIC, the more likely is a weak recommendation \\
\hline
\end{tabular}

reviewed for content and clarity by the subgroup members and leaders from the other subgroups, and questions were rewritten or eliminated after extensive discussion and according to group consensus. This process resulted in five questions.

In the next step, the safety subgroup assigned one or two members to search the literature for evidence to answer each of the questions. The literature search was performed in a minimum of one general database (i.e., MEDLINE and EMBASE) and the Cochrane libraries, including article pertaining to COVID-19, SARS, MERS, and other respiratory viruses.

Search techniques. In the next step, the safety subgroup assigned one or two members to search the literature for evidence to answer each of the questions. The literature search followed the same techniques, as previously described. ${ }^{1}$ The literature search was performed in a minimum of one general database (i.e., MEDLINE and EMBASE) and the Cochrane libraries, including article pertaining to COVID-19, SARS, MERS, and other respiratory viruses. The terms low-resource setting and LMIC were also added to the search, but in cases were adding these terms resulted in no results, we appraised the literature from high-income countries and adapted the results to constrains usually present in LMICs. Furthermore, the subgroup members also searched for unpublished study results and included references suggested by group members, when relevant.

Grading of Recommendations. The subgroup members classified quality of evidence as high, moderate, low, or very low and recommendations as strong or weak. The factors influencing this classification are presented in Table A1.

The subgroup members paid extensive attention to several other factors as used before, but now focusing on LMICs, that is, availability and feasibility in LMICs, and safety matters in LMICs. A strong recommendation was worded as "we recommend" and a weak recommendation as "we suggest." Recommendations could remain "ungraded" (UG), when, in the opinion of the subgroup members, such recommendations were not conducive for the process described above (Table A2).

Reporting. The report was edited for style and form by Alfred Papali or Marcus Schultz, with final approval by subgroup leaders and then by the entire "COVID-LMIC Task Force." A final document was submitted to the "American Journal of Tropical Medicine and Hygiene" for potential publication as a 1,000-word article and made open access.

Acknowledgements: No members of the 'safety' subgroup represented industry, and there was no industry input into guidelines development. No member of the 'safety' subgroup received honoraria for any role in the guideline development process. None reported conflicts of interest. Open access fees for this manuscript, and all 9 others in the series, were supported by the Wellcome Trust of Great Britain.

\section{REFERENCE}

1. Dondorp AM, Dünser MW, Schultz MJ, eds., 2019. Sepsis Management in Resource-Limited Settings. Cham, Switzerland: Springer. doi: 10.1007/978-3-030-03143-5. 